\title{
Characterization of Ionospheric Scintillation Index over low latitude: Nepal Region
}

\author{
Kutubuddin Ansari ${ }^{1 *}$, Tae-Suk Bae ${ }^{1}$, Punyawi Jamjareegulgarn ${ }^{2}$, Shakera Khan $^{3}$, Soo-Hyeon Lim ${ }^{1}$ \\ ${ }^{1}$ Department of Geoinformation Engineering, Sejong University, Seoul, South Korea \\ ${ }^{2}$ Department of Engineering, KMITL, Prince of Chumphon, Chumphon, Thailand \\ ${ }^{3}$ Deaprtment of Biotechnology, Suresh Gyan Vihar University, Jaipur, India \\ *Corresponding author: Kutubuddin Ansari, e-mail address: kdansarix @gmail.com
}

\begin{abstract}
The ionospheric scintillation is a rapid phase and amplitude fluctuation of satellite signals due to the small-scale irregularity of electron density in the ionosphere. The characterization of the scintillation index in a proper way is a crucial aspect of the Global Positioning System (GPS) satellite signals for the purpose of space-based navigation, satellite communication, space weather as well as earth observation applications. In the current study, we analyzed the ionospheric scintillation index during the year of 2018 to 2019 over the Nepal region which locates itself almost being sandwiched between India and China and in the vicinity of low latitudes. The characteristic variations of scintillation occurrence are studied during the several geomagnetic storm and quiet days. The results show that the S4 indexes are varying from the 0.05 to 0.45 during the whole year. The S4 indexes behave higher variations during the whole day in the starting of the year and start to decrease at end of the day as well as at the ending months of the year 2019. The S4 values become completely less during the sunset time, while they have higher values during the sunrise. Especially, the S4 index during the storm days are larger than during the quiet days. It is worthy to note that the variations of S4 index studied in this current study do not follow the sunset property during the year of 2019. Consequently, the causes should be discovered and discussed additionally in the next research paper.
\end{abstract}

Keywords: Ionosphere, Nepal, Scintillation index, Storm days, Quiet days

\section{Introduction}

The ionospheric irregularities in the low latitude and equatorial regions are remained a challenging task for the ionospheric investigators in the last decades. The issue of ionospheric irregularities is mainly related to the complex interaction of several physical activities which are responsible for large scale growth and decay in F region are known as plasma bubbles (Srinivasu et al., 2018). The phase and amplitude of the radio waves during the passing through the ionospheric F region fluctuate rapidly and randomly are called scintillations. These scintillations sometimes effect the and creates issue on the well performing of the navigation and communication system (Wernik, Alfonsi, \& Materassi, 2007). This type of events generally occurs during the dusk or after the dusk in the equatorial regions, may occur at any daytime at the polar regions. It is noticed mainly at the equatorial areas, least at mid-latitude while lesser at high-latitude regions (Akala et al., 2012). Global Positioning System (GPS) signal travel from satellite to the receiver are used to monitor the atmospheric error such as ionosphere and troposphere as well as crustal deformation (Ansari \& Corumluoglu, 2016; Ansari, Althuwaynee, \& Corumluoglu, 2016; Ansari, 2014). Ionospheric scintillations are able to reduce the phase and pseudorange measurements accuracy and sometimes may 
become responsible for significant weakening in accuracy of GPS or even lead to a complete failure of the system (Moraes et al., 2014). The scintillation, in extreme cases can be cause of full disturbance for the operating receiver (Rezende et al., 2007). Hence, the scintillation mitigation is a complex process for dualfrequency GNSS receivers. It is well-known that the scintillation occurrence is related to solar activity, local time, season, geomagnetic activity, and geographical location. The accurate positioning and signal availability of space and ground based augmentation systems (SBAS and GBAS) have been affected during extreme equatorial ionospheric scintillations. Moreover, during severe scintillations, the carrier-to-noise ratio below $30 \mathrm{~dB}-\mathrm{Hz}$ can result in the satellite signal outages. Several studies on the distribution and morphology of scintillation known as "scintillation climatology" is very important so as to mitigate the above-mentioned problems. Several observations related to climatology and dynamics of irregularities near the equatorial low-latitude zone have been reported earlier. For example, Sreeja et al. (2012) investigated the correlation between scintillation levels and Global Navigation Satellite System (GNSS) receiver tracking performance for both Global Positioning System (GPS) and GLONASS signals. Their results showed that the signals with lower transmitting frequency are more affected under scintillation. Meanwhile, Moraes et al. (2012) investigated the fading characteristics based on one month's scintillation data collected at low latitudes and built the relationship between fading duration and the occurrence probability of cycle slips. They found that the performance of a GPS receiver with CNR (carrier-to-noise ratio) threshold around or higher than $30 \mathrm{~dB}-\mathrm{Hz}$ could be severely influenced by deep fading. Afterwards, Jiao et al. (2016) studied the scintillation characteristics on GPS L1, L2C and L5 signals at the equatorial region. They reported that the fading rarely occurs on all GPS bands at the same time. Likewise, Seo et al. (2016) studied the signal fading because of ionospheric scintillation by using the intermediate frequency (IF) data and a commercial software receiver. Here, a fading model was also constructed to be beneficial for designing an aviation receiver. Moreover, Srinivasu et al. (2018) reported the scintillation effects on various types of GNSS signals over Indian zone using the multi-GNSS observations. They found that the impact of scintillation intensity also relies on the visible satellites of selected GNSS system in conjunction with solar and seasonal effects. The characteristics of temporal and spatial amplitude scintillations and their distributions of percentage occurrence during year 2013 are also studied over both Indian equatorial station, Bengaluru and EIA region, Lucknow (Sahithi et al., 2019). Here, the impact of geomagnetic quiet and disturbed days in the high solar activity period of the 24th solar cycle has also been investigated on GNSS systems. Although numerous literatures have been proposed to investigate the ionospheric scintillation in different parts of the globe, however, the scintillation has never been studied over Nepal region, an interesting boundary between low latitude and midlatitude. Therefore, we studied and analyzed the ionospheric scintillation index during the year of 2018 to 2019 over Nepal region in the vicinity of low latitudes in this current study. The characteristic variations of scintillation occurrence are studied during the several geomagnetic storm and quiet days. The main objective of this study is to understand the probability of scintillation occurrence over Nepal region. 


\section{Data Used}

In the present study, we tried to investigate the effects of scintillation over the GPS sites from Nepal during the year of 2018 and 2019. Geographically the boundary of Nepal is presented by trapezoidal (approximately) shape with length and width of 800 and $200 \mathrm{~km}$ respectively (area around 147,181 km²). In terms of geographical coordinates, the country lies between $26^{\circ}$ to $31^{\circ} \mathrm{N}$ latitudinal and $80^{\circ}$ to $89^{\circ} \mathrm{E}$ longitudinal directions (Ansari, 2018; Ansari et al., 2019). The major part of the country is surrounded by India from three sides (except north) while northern part is bounded by Tibet, China (Figure 1). The GPS observation data in rinex formats for five GPS sites all over Nepal has been accessed from UNAVCO archives (ftp://data-out.unavco.org/pub/rinex/) and processed with the GPS-TEC analysis software (Seemala \& Valladares, 2011). We chose the maximum elevation height $\left(\mathrm{h}_{\max }=350 \mathrm{~km}\right)$, the elevation angle $\left(\alpha=20^{\circ}\right)$, and the radius of the earth $\left(\mathrm{R}_{\mathrm{E}}=6378 \mathrm{~km}\right)$ during the processing of GPS data (Sharma, Ansari \& Panda, 2018).

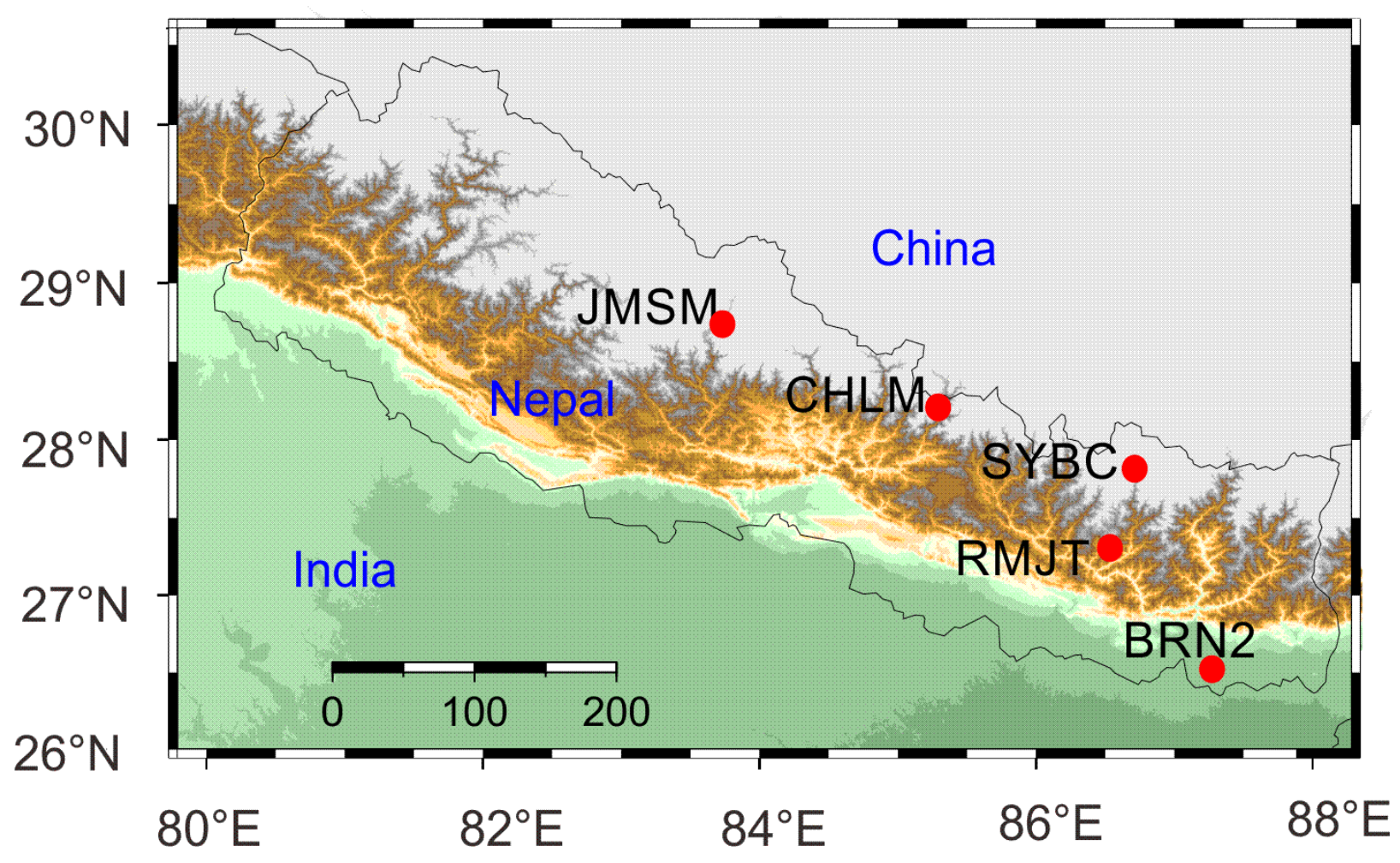

Figure 1 GPS selected sites over Nepal for the current study

\section{Ionospheric Scintillation Index}

Ionospheric scintillation is a stochastic (random) phenomenon concerning the phase and amplitude fluctuations of GNSS signals. In severe situations, the scintillation can lead to the loss of signal locking (or cycle slip). It is worthy to note that the effects of scintillation are not removed by dual-frequency observations. Hence, Trimble has formulated a global ionospheric scintillation sounding network to detects scintillation effects and provides up-to-date warning information on scintillation effects in different parts of 
the globe. The scintillation generally occurs in equatorial regions after sunset for several hours, whereas it can exist at any time over polar regions. A map showing the current ionospheric scintillation activity can be found on the http://www.trimbleionoinfo.com/Images.svc/SCINTI. The intensity of amplitude scintillation is commonly indicated by amplitude scintillation (S4 index), which is the normalized standard deviation of the signal power/intensity, given by (Dierendonck \& Arbesser-Rastburg 2004). The scintillations index climatological amplitude for the geomagnetic quiet and disturbed days during the investigation period (2018 - 2019) is conversed according to the geomagnetic Dst index. The scintillation amplitude is measured by computing the $\mathrm{S} 4$ index. The occurrence percentage of S4 index is calculated by the following expression.

$$
\text { Percentage of Occurrence }=\frac{\mathrm{x}(\mathrm{S} 4>\text { Threshold })}{\mathrm{Xtotal}}
$$

where X stand for the S4 index amplitude sample space and Xtotal means the total number of S4 values. Generally, the S4 amplitude is characterized as a strong scintillation when S4 > 0.8, moderate scintillation when $0.5<\mathrm{S} 4<0.8$ and weak scintillation when $0.2<\mathrm{S} 4<0.5$ (Abadi, Saito, \& Srigutomo, 2014). The threshold value can be chosen any number, for example, the threshold value 0.2 is chosen by Sahithi et al. (2019) in their investigation. In the current study we took the threshold value of 0.05 .

\section{Result and Discussion}

The daily variation of S4 values during the year of 2019 is shown in Figure 2. The horizontal axis in given figure shows the daily (or monthly) variation of $\mathrm{S} 4$ and the vertical axis presents the local time. The color bar in the figure is the indication of S4 variation. It is clear from the figure that the S4 values during the whole year are varying from the 0.05 to 0.45 . The S4 indexes have higher variations during the whole day in the starting of the year. These values start to decrease at end of the day and at the ending months of the year 2019. The S4 values become completely less during the sunset time, while they have higher values during the sunrise. The observed scintillation peak during the noon time possibly related to the precipitation into the daytime (Tiwari et al., 2012). As we already discussed in the introduction section that the ionospheric scintillation is a phenomenon that occurs after sunset, especially in the low-latitude regions, affecting radio signals that propagate through the ionosphere. Here, Nepal is in the upper low latitude region, but the variations of S4 index do not follow the sunset property during the year of 2019. These are the complicated issues which we need to find the causes. Here, we presented the initial results, and then we will try to discuss more analysis in the next research paper. 


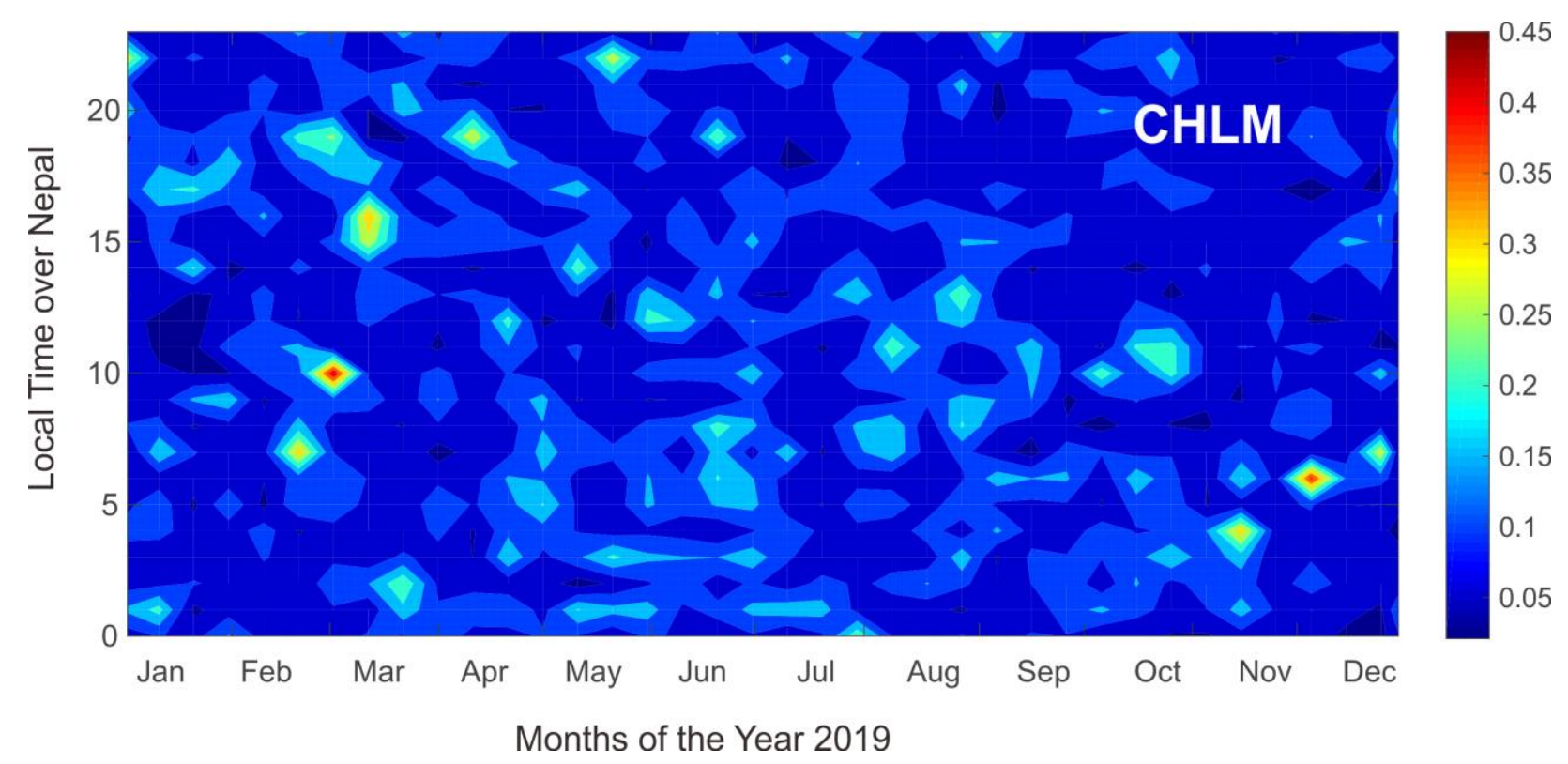

Figure 2 Annual variations of amplitude scintillations over CHLM stations during the year 2019

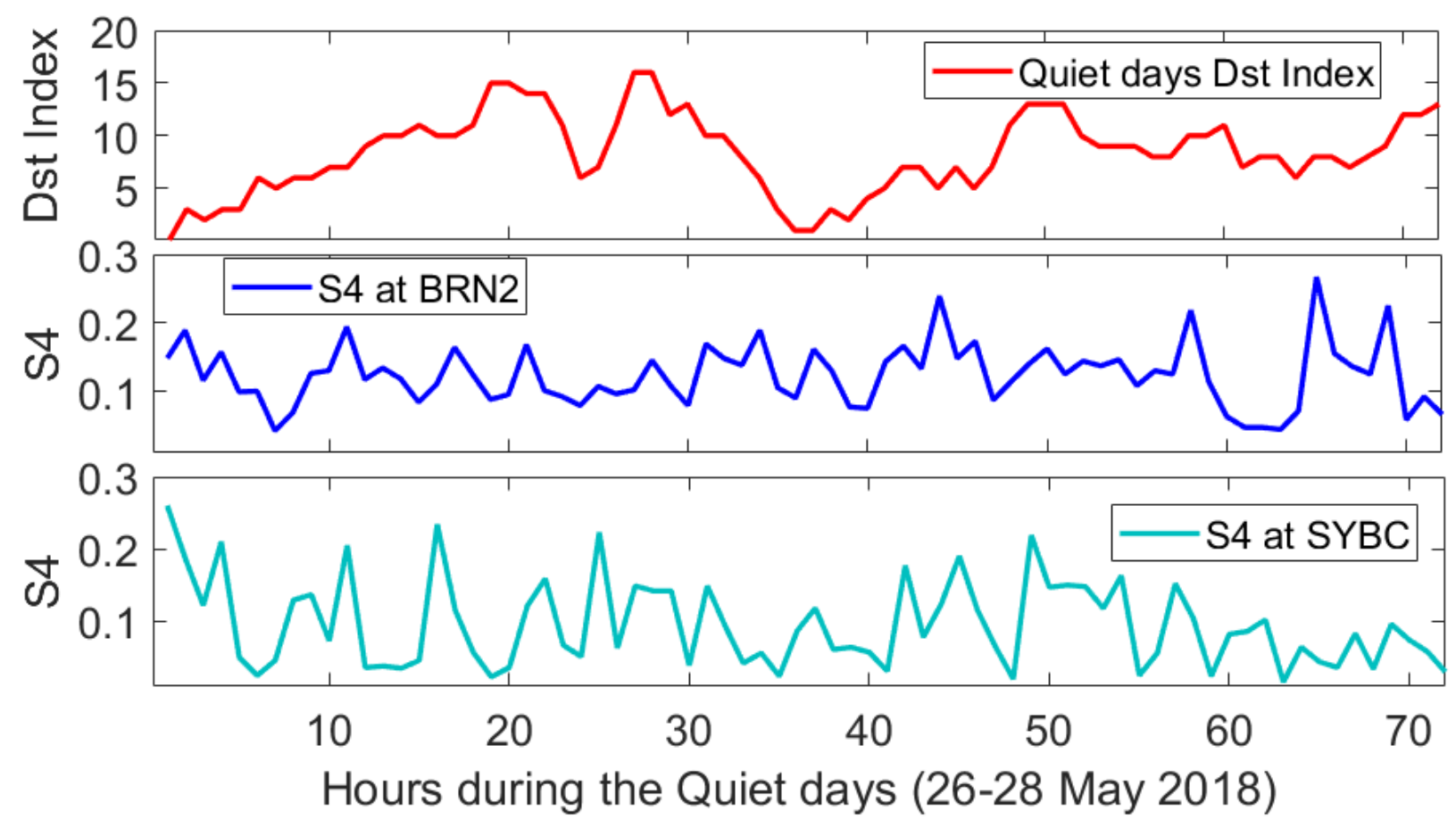

Figure 3 The temporal variations of S4 Index values representing the amplitude scintillations at BRN2 and SYBC during the quiet days (26-28 May 2018) with respect to Dst Index

We selected the quiet days (26 - 28 May 2018) S4 index variation two selected GPS sites over Nepal named BRN2 and SYBC as shown in Figure 3. We can see from the top panel of the figure that Dst values are varying from 0 to 20 which indicates the geomagnetic quiet days. The $S 4$ values in figure are lies between 0.05 to 0.30. Similarly, the for the storm days we choose the days (25 - 27 Aug 2018) S4 index and plotted them with Dst index as shown in Figure 4. It is clear from Dst index that lies between around -180 to 20 presenting storm days effect. The value of S4 during the storm days is noted around 0.05 to 0.40 which means that the S4 index during the storm days are larger compared to the quiet days. The same results can 
be found and discussed additionally in Tiwari et al. (2012). The occurrence of scintillations is increasing as Dst increased indicates the dependency on magnetic activity. This happened due the large-scale ionospheric structure of enhanced electron density during the storm days compared to quiet days. These variations may be associated with the occurrence of the polar patches which increased about 2 TEC units in the duration of about 30 minutes (Basu et al., 1998). The high electron density polar patches generate scintillation in the signal and large enhancement in the TEC values (Basu et al., 1998; Tiwari et al., 2012).

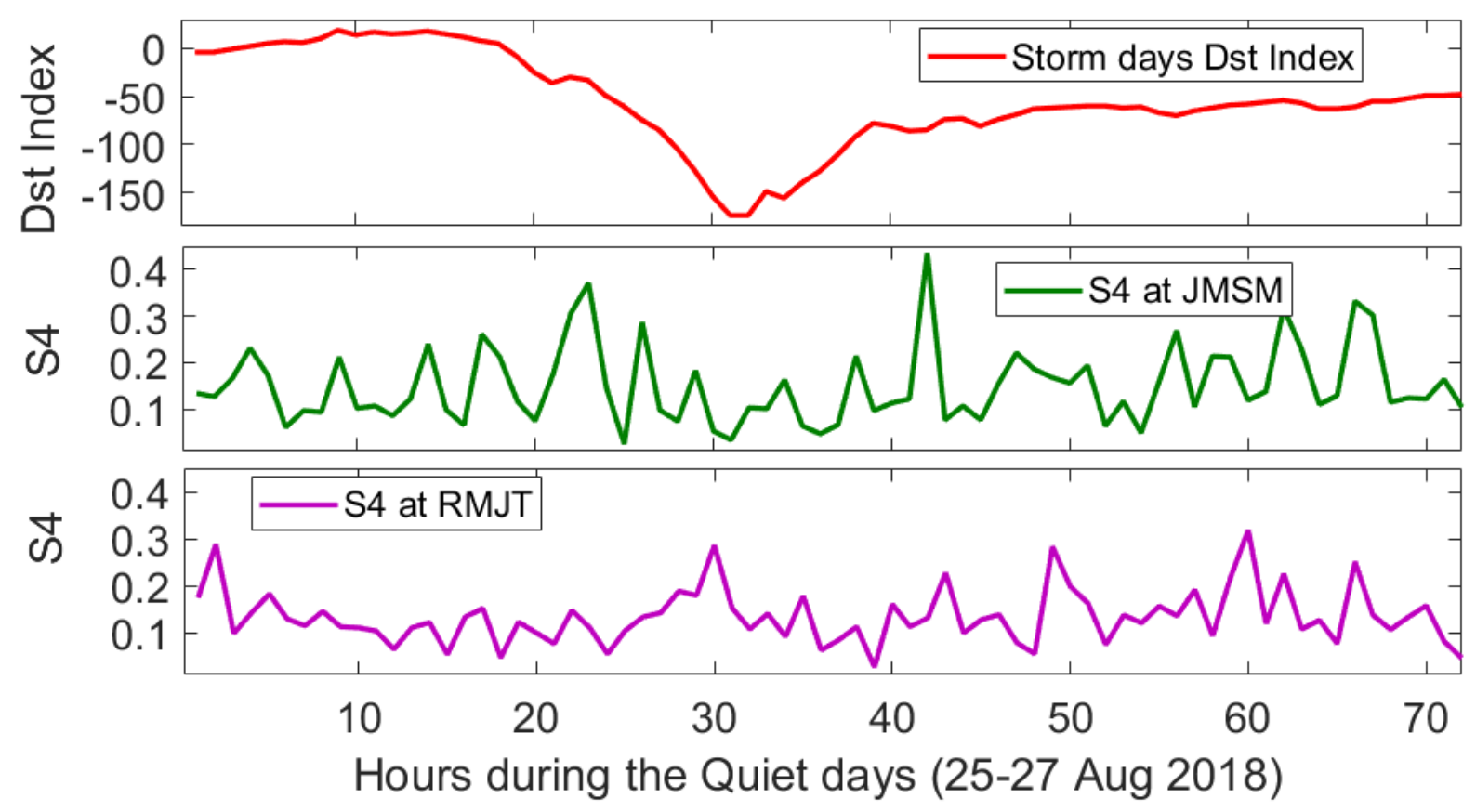

Figure 4 The temporal variations of S4 Index values representing the amplitude scintillations at JMSM and RMJT during the storm days (25-27 Aug 2018) with respect to Dst Index

\section{Conclusion}

We used the GPS data located over Nepal for the year of 2018 and 2019 and investigated the S4 index variation during the diurnal, quit and storm days. The S4 values become completely less during the sunset time, while they have higher values during the sunrise in the year of 2019. The S4 values are higher during the storm days, while they are low values during the quiet days in the year of 2019. These are the just initial results; we will thoroughly discuss about the results in our next research paper. Finally, we hope that our proposed approach in this current study will help to understand the probability of scintillation occurrence over Nepal region. 


\section{Acknowledgements}

This research is financially supported by academic melting pot of KMITL research fund (grant No. KREF 206238). The authors are appreciated to both Caltech Tectonics Observatory and UNAVCO (ftp://data-out.unavco.org/pub/rinex/) for providing the GPS data of several stations over Nepal region. We also thank sincerely to Seemala and Valadares for providing TEC analysis and to the reviewers for their useful comments and suggestions.

\section{References}

Abadi, P., Saito, S., \& Srigutomo, W. (2014). Low-latitude scintillation occurrences around the equatorial anomaly crest over Indonesia. Annales Geophysicae, 32(1), 7-17, DOI: 10.5194/angeo-32-7-2014

Akala, A. O., Doherty, P. H., Carrano, C. S., Valladares, C. E., \& Groves, K. M. (2012). Impacts of ionospheric scintillations on GPS receivers intended for equatorial aviation applications. Radio Science, 47(04), 1-11.

Ansari, K., Althuwaynee, O. F., \& Corumluoglu, O. (2016). Monitoring and prediction of precipitable water vapor using GPS data in Turkey. Journal of applied geodesy, 10(4), 233-245.

DOI: $10.1515 /$ jag-2016-0037

Ansari, K., Gyawali, P., Pradhan, P.M., \& Park, K. D. (2019). Coordinate transformation parameters in Nepal by using neural network and SVD methods. Journal of Geodetic Science, 9(1), 22-28, DOI: 10.1515/jogs-2019-0003

Ansari, K. \& Corumluoglu, O. (2016). Ionospheric observation over Turkey by using Turkish permanent GPS stations. International Conference on Agricultural, Civil and Environmental Engineering (ACEE-16), Istanbul, Turkey, 32-36. DOI: 10.17758/URUAE.AE0416224

Ansari, K. (2014). Quantification of slip along deformation using Finite Element Method. Journal of research in environmental and earth sciences, 1(1), 25-28.

Ansari, K. (2018). Crustal deformation and strain analysis in Nepal from GPS time-series measurement and modeling by ARMA method. International Journal of Earth Sciences, 107(8), 2895-2905, DOI: $10.1007 / \mathrm{s} 00531-018-1633-7$

Basu, S., Weber, E.J., Bullett, T.W., Keskinen, M.J., MacKenzie, E., Doherty, P., Sheehan, R., Kuenzler, H., Ning, P. and Bongiolatti, J. (1998). Characteristics of plasma structuring in the cusp/cleft region at Svalbard. Radio Science, 33(6), 1885-1899.

Dierendonck, A. J. V., Arbesser-Rastburg, B. (2004). Measuring Ionospheric scintillation in the equatorial region over Africa, including measurements from SBAS geostationary satellite signals. Proceedings of ION GNSS 2004, Long Beach, CA, 21-24 September 2004, 316-324.

Jiao, Y., Dongyang, X., Morton, Y., Rino, C. (2016). Equatorial scintillation amplitude fading characteristics across the GPS frequency bands. Navigation, 63, 267-281. DOI: 10.1002/navi.146

Moraes, A. D. O., Costa, E., De Paula, E. R., Perrella, W. J., \& Monico, J. F. G. (2014). Extended ionospheric amplitude scintillation model for GPS receivers. Radio Science, 49(5), 315-329.

Moraes, A. D. O., Rodrigues, F. D. S., Perrella, W. J., Paula, E. R. D. (2012). Analysis of the characteristics of low-latitude GPS amplitude scintillation measured during solar maximum conditions and implications for receiver performance. Surveys in Geophysics, 33(5), 1107-1131, DOI: 10.1007/s10712-011-9161-z

Rezende, L. F. C. D., De Paula, E. R., Kantor, I. J., \& Kintner, P. M. (2007). Mapping and survey of plasma bubbles over Brazilian territory. The Journal of Navigation, 60(1), 69-81.

Sahithi, K., Sridhar, M., Kotamraju, S. K., Kavya, K. C. S., Sivavaraprasad, G., Ratnam, D.V., \& Deepthi, 
C. (2019). Characteristics of ionospheric scintillation climatology over Indian low-latitude region during the 24th solar maximum period. Geodesy and Geodynamics, 10(2), 110-117.

Seemala, G. K., \& Valladares, C. E. (2011). Statistics of total electron content depletions observed over the South American continent for the year 2008. Radio Science, 46(5).

Seo J., Walter, T., Chiou, T. Y., Enge, P. (2016). Characteristics of deep GPS signal fading due to ionospheric scintillation for aviation receiver design. Radio Science, 44(1), 1-10, DOI: $10.1029 / 2008$ RS004077

Sharma, S. K., Ansari, K., \& Panda, S. K. (2018). Analysis of Ionospheric TEC Variation over Manama, Bahrain, and Comparison with IRI-2012 and IRI-2016 Models. Arabian Journal for Science and Engineering, 43(7), 3823-3830, DOI: 10.1007/s13369-018-3128-Z

Sreeja, V., Aquino, M., Elmas, Z. G., Forte, B. (2012). Correlation analysis between ionospheric scintillation levels and receiver tracking performance. Space Weather, 10(S06005), DOI: 10.1029/2012SW000769

Srinivasu, V. K. D., Dashora, N., Prasad, D. S. V. V. D., Niranjan, K., \& Krishna, S. G. (2018). On the occurrence and strength of multi-frequency multi-GNSS Ionospheric Scintillations in Indian sector during declining phase of solar cycle 24. Advances in Space Research, 61(7), 1761-1775.

Tiwari, S., Jain, A., Sarkar, S., Jain, S., \& Gwal, A. K. (2012). Ionospheric irregularities at Antarctic using GPS measurements. Journal of earth system science, 121(2), 345-353.

Wernik, A. W., Alfonsi, L., \& Materassi, M. (2007). Scintillation modeling using in situ data. Radio Science, $42(01), 1-21$. 